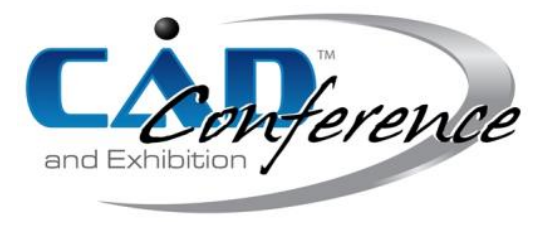

Title:

Product Radical Innovation based on Global Idealization

Authors:

Yafan Dong, dyafan@foxmail.com, Hebei University of Technology

Runhua Tan, rhtanhebut@163.com, Hebei University of Technology

Qingjin Peng, Qingjin.Peng@umanitoba.ca, University of Manitoba

Yunpeng Su, 1282875810@qq.com, Hebei University of Technology

Fei Yu, fyu@hebut.edu.cn, Hebei University of Technology

Xiangdong Li, lee96xd@163.com, Hebei University of Technology

Keywords:

Radical Innovation, TRIZ, Patent Analysis, Product Life Cycle, Global Idealization, Function Reorganization

DOI: 10.14733/cadconfP.2021.226-230

\title{
Introduction:
}

Product innovation is a process to constantly search idealization [6]. Radical innovation (RI) is required for product competition in the market using the key technology. Research shows that RI occurs in the mature stage of product life cycle [8]. The most of existing studies mainly accidentally form a RI solution without considering the long-time effect and high risk of the solution [1]. It is necessary to develop an effective RI method.

Idealization is an abstraction of objects and can be used in an innovative process. Global idealization considers the function forbidden, system forbidden and principle changed in a system. TRIZ (Invention Problem Solving Theory) provides tools to analyze and solve innovation problems $[2,4]$. In this paper, a design method of RI is proposed based on the global idealization. According to customer and market requirements, a target product is selected and developed based on the patent analysis using TRIZ tools. The occurrence stage of RI is identified by the patent search and analysis. The global idealization is implemented using trimming and function reorganization, such as resource analysis, function-oriented search (FOS) and effect search. Inventive problems are solved using TRIZ tools. Solutions are evaluated by the level of ideality based on the analytic hierarchy process (AHP) and RI definition. RI design of a dust-removal device on solar panels is developed using the proposed method.

\section{Main Ideas:}

Product RI occurs in the mature stage of product life cycle. It is believed that the result of RI can change product working principle, improves five or more times of performance, or reducing $30 \%$ or more cost $[8,9]$. Global idealization considers the product life cycle in the infancy stage, growth stage, maturity stage and withdrawal stage, as shown in Fig. 1 (a). These stages can be determined by the product maturity prediction and patent analysis.

Based on the four stages of the technology development, an innovation direction can be selected based on Fig. 1 (b). For the RI direction, according to the number of related patents such as invention patents, utility model patents and appearance patents, three statistical parameters can be obtained for a quantitative analysis of patents, namely technology growth rate $\mathrm{V}$, technology maturity coefficient $\alpha$, and technology aging coefficient $\beta$ [5], as shown in Eqns. (1), (2) and (3). 


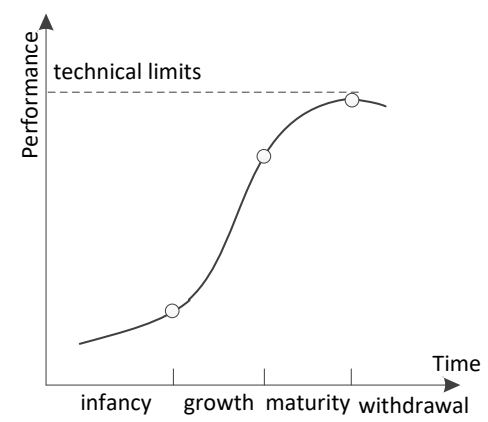

(a) S-curve of product life cycle

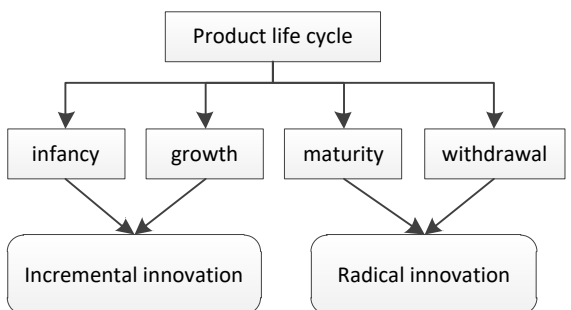

(b) decision-making of innovation direction

Fig. 1: Product maturity prediction and decision-making.

$$
\begin{gathered}
V=\frac{a}{A} \\
\alpha=\frac{a}{a+b} \\
\beta=\frac{a+b}{a+b+c}
\end{gathered}
$$

where $\mathrm{a}$ is the number of invention patent applications in the year, A is the total number of invention patent applications in the past five years, $b$ is the number of utility patent applications in the year, and $\mathrm{c}$ is the number of appearance patent applications in the year.

The product is in the infancy stage or growth stage when the linear fitting of $V$ is on the increase. Otherwise, you should see linear fitting trend of $\alpha$. A decreasing trend means that the technology becomes mature, the product is in the mature stage. If not, $\beta$ shows a decreasing trend, the product is in the withdrawal stage, as shown in Fig. 1 (b).

Trimming and resource analysis can remove harmful function, forbid auxiliary subsystem or change principle as shown in Tab. 1 [7]. The missed function is defined and generalized in a form of "verb + noun". Function reorganization is realized using the available resource analysis, FOS and effect search. When inventive problems are found, solutions can be obtained using TRIZ tools such as inventive principles and sub-field analysis. The goal of innovation is to continuously improve the level of product idealization. The idealization level can be expressed as follows.

$$
I=\sum U F / \sum H F
$$

where UF is useful functions; HF is harmful functions. In order to process the analysis conveniently, the idealization level can be expressed as Eqn. (5) based on Eqn. (4). Weight coefficients e and $h$ are determined used AHP in a pairwise comparison. Solutions are evaluated using Eqn. (5) and RI definition. Figure 2 shows a model of product RI using the global idealization based on patent analysis and TRIZ.

$$
I=\left(\frac{1}{m} \sum_{i=1}^{m} B_{i}\right) /\left(\frac{1}{m} \sum_{i=1}^{m} e \cdot E_{i}+\frac{1}{m} \sum_{i=1}^{m} h_{\bullet} H_{i}\right)
$$

where $\mathrm{m}$ is the number of system constituent elements; $B_{\mathrm{i}}$ is the benefit parameter to meet function requirements of product elements; $E_{\mathrm{i}}$ is the expense parameter affecting the realization of function requirements of elements; $H_{\mathrm{i}}$ is the harmful parameter affecting the realization of function requirements of elements; $e$ is the weight coefficient of expenses; $h$ is the weight coefficient of harms. 


\begin{tabular}{|c|c|c|c|}
\hline NO. & Graphic trimming & Illustration & Global idealization \\
\hline 1 & & $\begin{array}{l}\text { If there is no S2, the function of S1 is not } \\
\text { needed, and S1and F can be trimmed. So, } \\
\text { the function A is forbidden. }\end{array}$ & Function forbidden \\
\hline 2 & & $\begin{array}{l}\text { S2 can perform the function of S1 by } \\
\text { itself, and S1 can be trimmed. So, } \\
\text { subsystem S1 is forbidden. }\end{array}$ & System forbidden \\
\hline 3 & analysis & $\begin{array}{l}\text { Other existing unit in technology system } \\
\text { or supersystem can complete the } \\
\text { function of S1, and S1 can be trimmed. }\end{array}$ & Principle changed \\
\hline 4 & $\begin{array}{l}\text { resource } \\
\text { analysis }\end{array}$ & $\begin{array}{l}\mathrm{S} \text { is introduced from a new technology } \\
\text { system and can complete the function of } \\
\text { S1. S1 can be trimmed. }\end{array}$ & Principle changed \\
\hline
\end{tabular}

Tab. 1: Trimming based on global idealization.

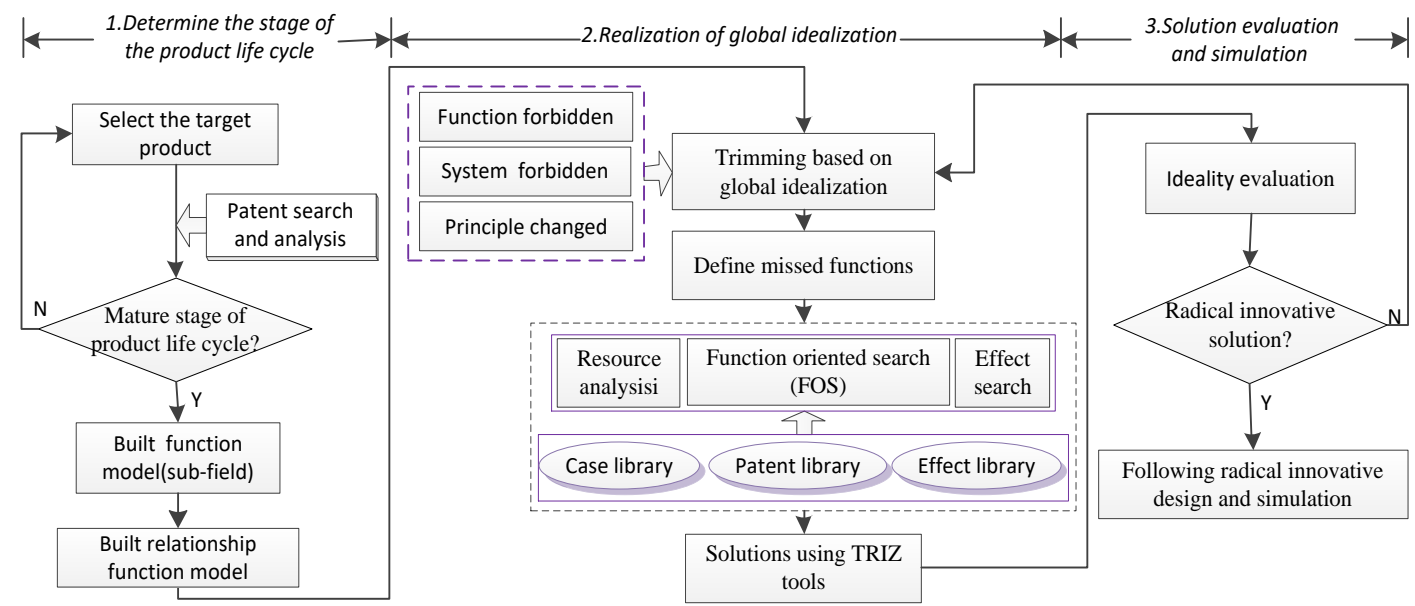

Fig. 2: Modeling of product RI using the global idealization.

\section{Case Study}

Solar energy is widely used as the green energy. Power generation by the solar energy uses photovoltaic and photothermal processes. Dust depositions on the solar panel will degrade the efficiency of the solar photovoltaic (PV) conversion, which has a great impact on the power generation efficiency and battery life of solar systems. Existing methods of the dust removal consider reducing dust on the solar panel in isolation, such as using compressed air on the solar panel to remove the dust, and the analysis of cloud-dust for the system performance [3]. It is therefore critical to have a comprehensive method to reduce the dust deposition on the solar panel for the efficient photoelectric conversion.

Solar panels are mostly fixed in installation without following changes of the sun direction. The solar panels cannot effectively receive the sunlight, which seriously affects the photoelectric conversion. Main ways of the dust removal of solar panels are the manual work, water syringe and 
waterless robot. However, these methods need extra resources, which greatly increases the cost of dust removal.

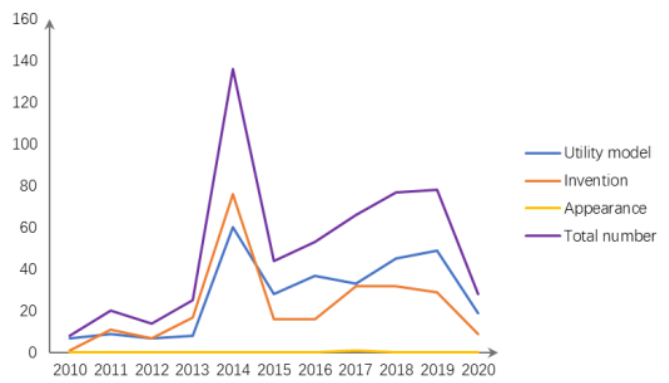

Fig. 3: Patents application in recent ten years.

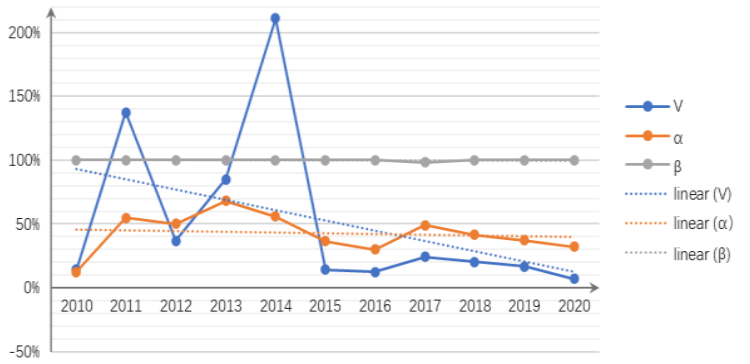

Fig. 4: Trends of three statistical parameters.

Using solar panel or photovoltaic panel and removing dust or impurity as key words, 1011 patents are searched using patsnap software. 562 effective patents are obtained by related screening. A trend of patent applications in recent ten years is as shown in Fig. 3. Using Eqns. (1), (2) and (3), trends of three statistical parameters $V, \alpha, \beta$ of the dust-removal system of solar panels are obtained as shown in Fig. 4. $\mathrm{V}$ and $\alpha$ decrease linearly in Fig. 4. Therefore, the dust-removal system of solar panels is in the mature stage. According to the function analysis, a function model of water syringe dust-removal device is built as shown in Fig. 5 .

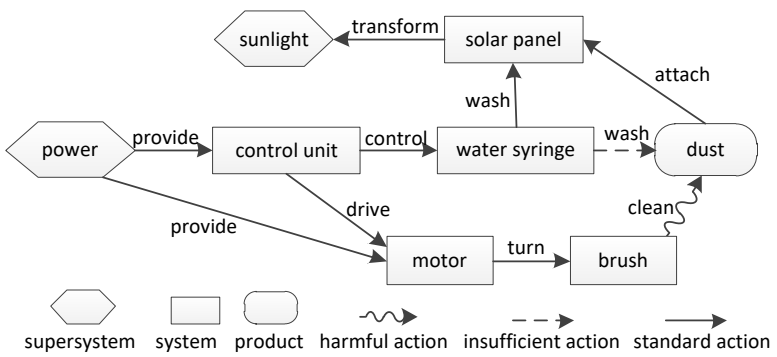

Fig. 5: Function model of the water syringe dust-removal device.

RI is conducted using trimming based on the global idealization and functional reorganization as shown in Fig. 2. Based on trimming principle in Table 1, the brush is trimmed as it may damage surfaces of solar panels in the dust-removal process. The motor is then trimmed. As water is lack in the northwest of China, the cost is very high if solar panels are washed by water. The water pistol is trimmed. Therefore, the control unit and power are trimmed as shown in Fig. 6. For illustration of function reorganization, the resource analysis is taken as an example. The wind resource is selected based on the available resource analysis as shown in Fig. 7.

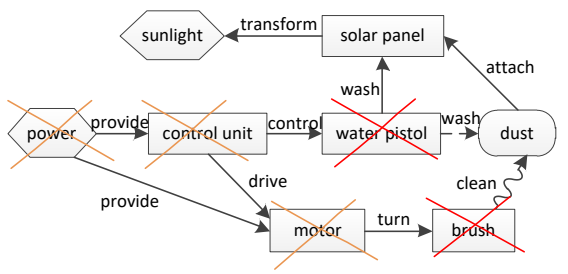

Fig. 6: The trimming function model.

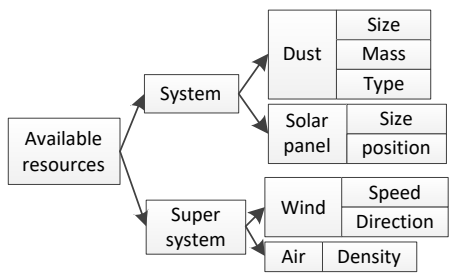

Fig. 7: The available resources.

When wind acts the dust on solar panels directly, it cannot remove dust effectively. There is an insufficient action between wind and dust. According to standard solution No.14(2.1.1)- series sub- 
field model in TRIZ, the wind amplification unit is introduced as shown in Fig. 8. Similarly, motors are added in the dust-removal device to track the direction of sunlight and wind. Finally, a solution is formed by the evaluation of ideality using Eqn. (5). The working principle of dust removal is changed as shown in Fig. 9. In addition, cleaning cloth is used based on gravitational potential energy. It mainly removes dust using wind by a wind amplification unit and track the direction of sunlight and wind to improve conversion efficiency and dust-removal effect.

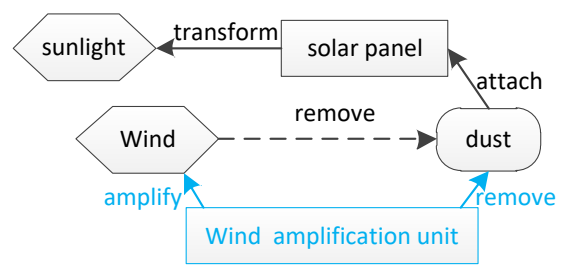

Fig. 8: Function model using sub-field.

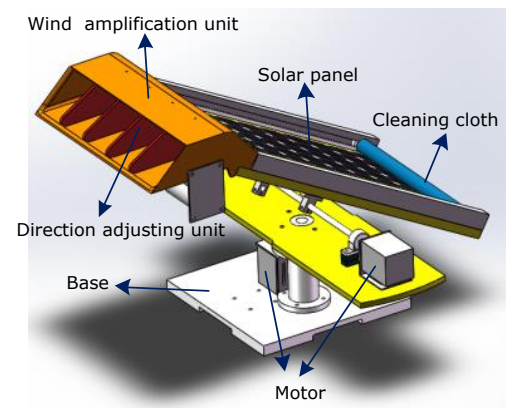

Fig. 9: Radical innovative Solution.

Conclusions:

A method of product RI was proposed using the global idealization based on the patent analysis and TRIZ. Photoelectric conversion performance of solar panels and dust depositions on solar panels were considered in the RI design. According to the patent search and analysis, a maturity prediction model was introduced to determine the occurrence stage of RI. The global idealization was used for RI design of a device to remove dust on solar panels using wind by tracking directions of sunlight and wind. The solution greatly improves the photoelectric conversion efficiency, reduces cost and saves energy.

Acknowledgements:

This research was funded by Chinese Industrial Internet innovation and development project (TC19083W8).

\section{References:}

[1] Chang, Y. C.; Chang, H. T.; Chi, H. R.: How do established firms improve radical innovation performance? The organizational capabilities view, Technovation, 32(7), 2012, 441-451.

[2] Dong, Y.; Peng, Q.; Tan, R.: Product Function Redesign Based on Extension Theory, ComputerAided Design \& Applications, 18(1), 2020, 199-210. https://doi.org/10.14733/cadaps.2021.199$\underline{210}$

[3] Huang, C. C.: Study on cloud-dust based intelligent maximum performance analysis system for power generation with solar energy, Scientia Iranica, 6(22), 2015, 2170-2177.

[4] Ilevbare, I. M.; Probert, D.; Phaal, R.: A review of TRIZ, and its benefits and challenges in practice, Technovation, 33(2-3), 2013, 30-37. https://doi.org/10.1016/j.technovation.2012.11.003

[5] Qing, Y. I.; Cheng, H. S.: Contrastive Analyze on Patent Information-The Case of Guangdong, Beijing and Shanghai, Information Science, 6(25), 2007, 838-843, 851.

[6] Savransky, S. D.: Engineering of creativity, CRC Press, New York, NY, 2000. https://doi.org/10.1201/9781420038958

[7] Sheu, D. D.; Hou, C. T.: TRIZ-based trimming for process-machine improvements: Slit-valve innovative redesign, Computers \& Industrial Engineering, 66(3), 2013, 555-566. https://doi.org/10.1016/j.cie.2013.02.006

[8] Tan, R. H.: C-TRIZ and the Application, Higher Education Press, Beijing, China, 2020.

[9] Wang, K.; Tan, R. H.; Peng, Q. J.: Radical innovation of product design using an effect solving

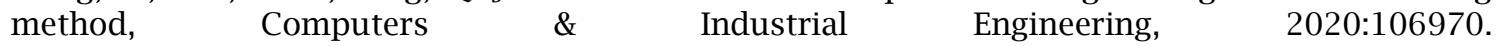
https://doi.org/10.1016/j.cie.2020.106970 